\title{
Modelling and Passivity-based Control of a Non Isolated DC-DC Converter in a Fuel Cell System
}

\author{
Moutabir Ahmed, Abdelmounim Elhassane, Aboulfatah Mohamed \\ L.A.S.T.I. University Hasan $1^{\text {st }}$, Faculty of Sciences and Technology of Settat, Settat, Morocco
}

\begin{tabular}{l}
\hline \hline Article Info \\
\hline Article history: \\
Received Feb 18, 2018 \\
Revised May 2, 2018 \\
Accepted May 11, 2018 \\
\hline
\end{tabular}

Keyword:

Cascaded boost

Euler lagrange

Fuel cell

Lyapunov

Passivity-based control

\begin{abstract}
This paper presents the model of a fuel cell and the design and simulation of a cascade of two DC-DC converters. First, a detailed mathematical model of fuel cell is presented and simulated. Then, a nonlinear model of the whole controlled system is developed and a robust nonlinear controller of currents is synthesized using a passivity-based control. A formal analysis based on Lyapunov stability and average theory is developed to describe the control currents loops performances. A classical PI controller is used for the voltages loops. The simulation models have been developed and tested in the MATLAB/SIMULINK. Simulated results are displayed to validate the feasibility and the effectiveness of the proposed strategy.
\end{abstract}

Copyright $\odot 2018$ Institute of Advanced Engineering and Science. All rights reserved.

\section{Corresponding Author:}

Moutabir Ahmed,

Hassan $1^{\text {er }}$ University FST Settat,

Settat, Morocco.

Email: moutabir_ahmed@hotmail.com

\section{INTRODUCTION}

In recent years, a rapid increase of the population of the world and a significant development of industries are the origine of increase of the demand of electricity. The use of renewable energies such as solar, wind or fuel cell can be a solution to this problem. To meet a part of his energy needs, morocco has developped several solar [1] and wind [2] sites in different regions. It also has an opportunity to develop hydrogen production.

The fuel cell is one of the most promising sources of renewable energy. They can be considered as green power because they are environmentally clean and have low emission of greenhouse gases, they can operate with a very low level of noise. In addition, they can provide energy in a controlled way with higher efficiency than conventional power plants.

Fuel cells are electrochemical devices which convert chemical energy into electrical energy directly by oxidizing fuel (hydrogen) without intermediate thermal or mechanical processes [3], [4]. They are efficient and silent devices that can provide power to a wide variety of utilities, from portable electronics to vehicles, to electric grids. They are categorized mainly on the type of electrolyte used, operating conditions or fuel.

In this work, the type of fuel cell considered is the Polymer Exchange Membrane Fuel Cell (PEMFC). Obtaining a high voltage is needed in some applications using a fuel cell.The problem can be handled either by using a simple step-up converter with high duty cycle or by using cascaded converters.

In this work, a cascaded boost DC-DC converter is used and designed by a nonlinear control strategy such as a passivity-based control.

Passivity-based control is essentially the control of energy. It has been utilized in some applications such as the DC-DC converters [5], [6], active power filters [7], [8] and controlled rectifiers [9], [10]. Using the passivity-based control can bring about good control effects on power electronic converters because it can 
accelerate the convergence of the energy function to the desired energy function under the precondition of system stability by properly injecting damping [11].

Some previous works have presented a studies of cascaded DC-DC converters in a fuel cell system controlled by a sliding mode strategy [12]-[14].

The paper is organized as follows: in Section 2, the fuel cell model is developed; in Section 3 the cascaded boost converter is described and modeled, Section 4 is devoted to designing the inner loop, using the passivity control, and the synthesis of the outer loop. The controller performances are illustrated by simulations in Section 5; a conclusion and a reference list end the paper.

\section{FUEL CELL MODEL}

Generally, the electrochemical operation principle of a PEM fuel cell is described by two chemical reactions and may be summarized as follows:

a. In anode, the oxidation reaction is given by: $\quad \mathrm{H} 2 \rightarrow 2 \mathrm{H}++2 \mathrm{e}-$

b. In the cathode, the reduction reaction is given by: $1 / 2 \mathrm{O} 2+2 \mathrm{H}++2 \mathrm{e}-\rightarrow \mathrm{H} 2 \mathrm{O}$

c. The overall reaction is:

$\mathrm{H} 2+1 / 2 \mathrm{O} 2 \rightarrow \mathrm{H} 2 \mathrm{O}$

The model of PEM fuel cell proposed in Reference [15] is considered in this paper.

The output voltage of a stack is given by:

$$
V_{F C}=\frac{V_{N}}{\left(1+\left(\frac{i_{F C}}{I_{h}}\right)^{\sigma}\right.}
$$

$V_{N}$ is the open stack voltage, $V_{F C}$ and $i_{F C}$ are respectively the voltage and current of fuel cell, $\sigma$ and $I_{h}$ are two parameters experimentally defined.

Using the values in Table 1, the simulation of the PEM fuel cell model has been using Matlab software gives a graph of voltage versus current Figure 1 bellow:

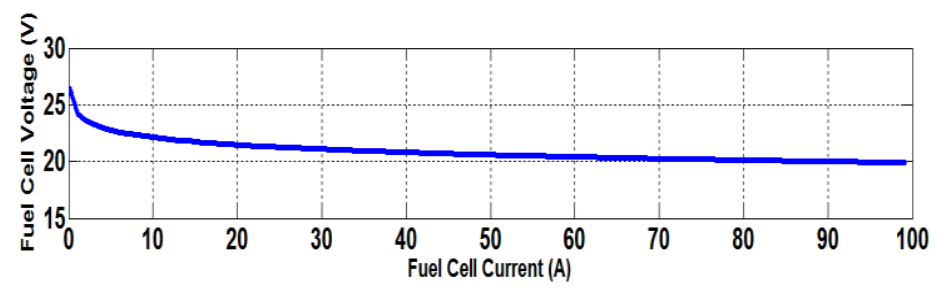

Figure1. The fuel cell voltage versus current

For the rest of study, it was considered that the energy provided by the fuel cell is in the linear zone "ohmic region", where the fuel cell deliver a stable power.

\section{DC-DC CONVERTER MODELLING}

The circuit topology of the cascaded boost DC-DC converter is shown in Figure 2.

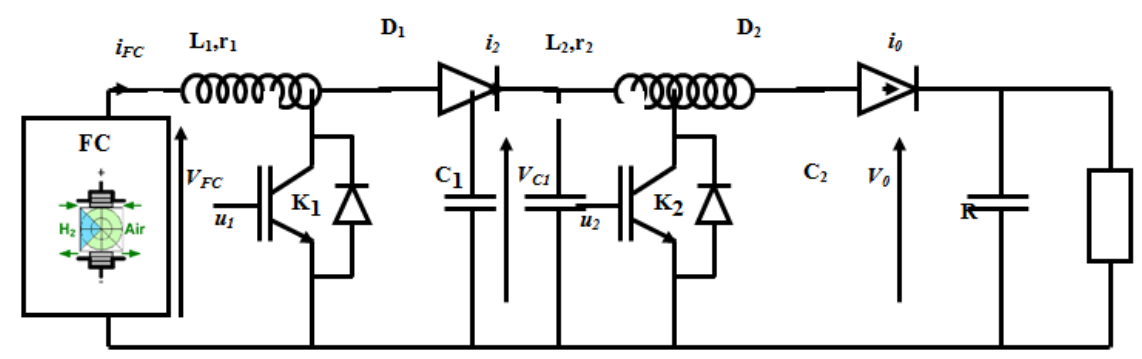

Figure 2. the cascaded boost DC-DC converter scheme 
The used parameter values of the present converter are depicted in Table 1.

Table 1. The used Parameter Values for the System

\begin{tabular}{|c|c|c|c|c|c|c|c|}
\hline Parameter & Value & Prameter & Value & Prameter & Value & Prameter & Value \\
\hline$\sigma$ & 0,335 & $\begin{array}{c}\text { Number of } \\
\text { cell }\end{array}$ & 22 & Inductors & $\begin{array}{l}L_{1}=35 \mu H \\
L_{2}=100 \mu H\end{array}$ & $\begin{array}{l}\text { Fuel cell } \\
\text { voltage }\end{array}$ & $V_{F C}=12 \mathrm{~V}$ \\
\hline$I_{h}$ & 483,2 & $V_{N}$ & $26 \mathrm{~V}$ & Capacitors & $\begin{aligned} C_{1} & =4 m F \\
C_{2} & =600 \mu F\end{aligned}$ & Load resistor & $R=10 \Omega$ \\
\hline$P_{F C}$ & $1,2 \mathrm{~kW}$ & & & Frequency & $10 \mathrm{kHz}$ & Swiches & IGBT \\
\hline
\end{tabular}

\subsection{Switched model}

The cascaded Boost converter can be represented by the following differential equations

$$
\begin{aligned}
& L_{1} \frac{d i_{1}}{d t}=V_{F C}-r_{1} i_{1}-\left(1-\mu_{1}\right) V_{C 1} \\
& C_{1} \frac{d V_{C 1}}{d t}=\left(1-\mu_{1}\right) i_{1}-i_{2} \\
& L_{2} \frac{d i_{2}}{d t}=V_{C 1}-r_{1} i_{2}-\left(1-\mu_{2}\right) V_{O} \\
& C_{2} \frac{d V_{O}}{d t}=\left(1-\mu_{2}\right) i_{2}-\frac{V_{0}}{R}
\end{aligned}
$$

Where $i_{1}$ and $i_{2}$ are, respectively, the currents in inductors $L_{1}$ and $L_{2}, r_{1}$ and $r_{2}$ are respectively the series resistor of inductors $L_{1}$ and $L_{2}, V_{c 1}$ denotes the voltage in capacitor $C_{1}$ and $V_{O}$ is the output voltage. $\mu_{1}$ and $\mu_{2}$ are denoted the duties ratio functions defined by

$$
\mu_{1}=\left\{\begin{array}{l}
1 \text { if } K_{1} \text { is } O N \\
0 \text { if } K_{1} \text { is } O F F
\end{array} \quad \text { and } \quad \mu_{2}=\left\{\begin{array}{l}
1 \text { if } K_{2} \text { is } O N \\
0 \text { if } K_{2} \text { is } O F F
\end{array}\right.\right.
$$

The averaged model is defined as follows:

$$
\begin{aligned}
& \dot{x}_{1}=-\frac{r_{1}}{L_{1}} x_{1}-\frac{1-u_{1}}{L_{1}} x_{2}+\frac{V_{F C}}{L_{1}} \\
& \dot{x}_{2}=\frac{1-u_{1}}{C_{1}} x_{1}-\frac{1}{C_{1}} x_{3} \\
& \dot{x}_{3}=-\frac{r_{2}}{L_{2}} x_{3}+\frac{1}{L_{2}} x_{2}-\frac{1-u_{2}}{L_{2}} x_{4} \\
& \dot{x}_{4}=\frac{1-u_{2}}{C_{2}} x_{3}-\frac{1}{R C_{2}} x_{4}
\end{aligned}
$$

In the above model $x_{1}, x_{2}, x_{3}, x_{4}$ are denoted, respectively, the averages currents and voltages $i_{1}, V_{C l}, i_{2}, V_{O}$ and $\left(u_{1}, u_{2}\right)$ represents the averages duties ratio function $\left(\mu_{1}, \mu_{2}\right)$.

\subsection{Establishment of euler lagrange model for DC-DC converter}

These equations can be rewritten in Euler-Lagrange (EL) form as follows:

$$
\mathcal{D} \dot{x}+\mathfrak{I} x+\mathcal{R} x=\mathcal{E}
$$

Where $\mathbf{x}$ is the system state variable vector, $\mathcal{D}$ is the positive definite diagonal matrix, $\mathfrak{J}$ is the antisymmetric matrix $\left(\mathfrak{J}=-\mathfrak{J}^{T}\right.$ ) which reflects the system internal interconnection structure; $\mathcal{R}$ is the system dissipation element matrix which reflects the system dissipation characteristics and $\mathcal{E}$ is the system external input vector.

The detailed expressions of these matrices are listed as follows:

$$
x=\left(\begin{array}{llll}
x_{1} & x_{2} & x_{3} & x_{4}
\end{array}\right)^{T}, \quad \mathcal{E}=\left(\begin{array}{llll}
V_{F C} & 0 & 0 & 0
\end{array}\right)^{T}
$$




$$
\begin{aligned}
\mathcal{D} & =\left(\begin{array}{cccc}
L_{1} & 0 & 0 & 0 \\
0 & C_{1} & 0 & 0 \\
0 & 0 & L_{2} & 0 \\
0 & 0 & 0 & C_{2}
\end{array}\right), \mathfrak{I}=\left(\begin{array}{cccc}
0 & 1-u_{1} & 0 & 0 \\
-\left(1-u_{1}\right) & 0 & 1 & 0 \\
0 & -1 & 0 & 1-u_{2} \\
0 & 0 & -\left(1-u_{2}\right) & 0
\end{array}\right) \\
, \mathcal{R} & =\left(\begin{array}{cccc}
r_{1} & 0 & 0 & 0 \\
0 & 0 & 0 & 0 \\
0 & 0 & r_{2} & 0 \\
0 & 0 & 0 & 1 / R
\end{array}\right)
\end{aligned}
$$

\subsection{Equilibrium points}

The equilibrium point can be obtained by forcing the time derivative of the state variables of the reduced order model to be null while letting the averages controls inputs $u_{1}$ and $u_{2}$ to adopt respectively the constant values $U_{1}^{0}$ and $U_{2}{ }^{0}$. As a result, we obtain a simple linear system of equations for the steady state equilibrium values of the average state variables [16].

Using the average state representation where we take into account that: $r_{1}=r_{2}=0$ and solving the system of equations for the unknowns $x_{1}{ }^{0}, x_{2}{ }^{0}, x_{3}{ }^{0}$ and $x_{4}{ }^{0}$, we obtain the equilibrium state of the system as:

$$
\dot{x}=0 \Rightarrow\left\{\begin{aligned}
x_{1}^{0} & =\frac{1}{\left(1-U_{1}^{0}\right)^{2}\left(1-U_{2}^{0}\right)^{2}} \frac{V_{F C}}{R} \\
x_{2}^{0} & =\frac{V_{F C}}{1-U_{1}^{0}} \\
x_{3}^{0} & =\frac{V_{F C}}{R\left(1-U_{1}^{0}\right)\left(1-U_{2}^{0}\right)^{2}} \\
x_{4}^{0} & =\frac{1}{\left(1-U_{1}^{0}\right)\left(1-U_{2}^{0}\right)} V_{F C}
\end{aligned}\right.
$$

The equilibrium point is noted by

$$
\begin{aligned}
& X^{0}=\left(\begin{array}{llllll}
x_{1}^{0} & x_{2}^{0} & x_{3}^{0} & x_{4}^{0}
\end{array}\right)=\left(\begin{array}{llll}
100 & 70 & 14 & 140
\end{array}\right) \\
& U^{0}=\left(\begin{array}{lll}
U_{1}^{0} & U_{2}^{0}
\end{array}\right)=\left(\begin{array}{ll}
0.83 & 0.5
\end{array}\right)
\end{aligned}
$$

From the equilibrium point, the output power is equal to the input power and that the input voltage in a boost converter is less than its output voltage.

\section{CONTROL DESIGN}

There are two operational control objectives:

a. Regulating the output voltage $x_{4}$ to a desired value $x_{4}^{*}$.

b. Ensure the global stability of the system.

c. Ensure the robustness of the system.

The control laws are illustred by the Figure 3.

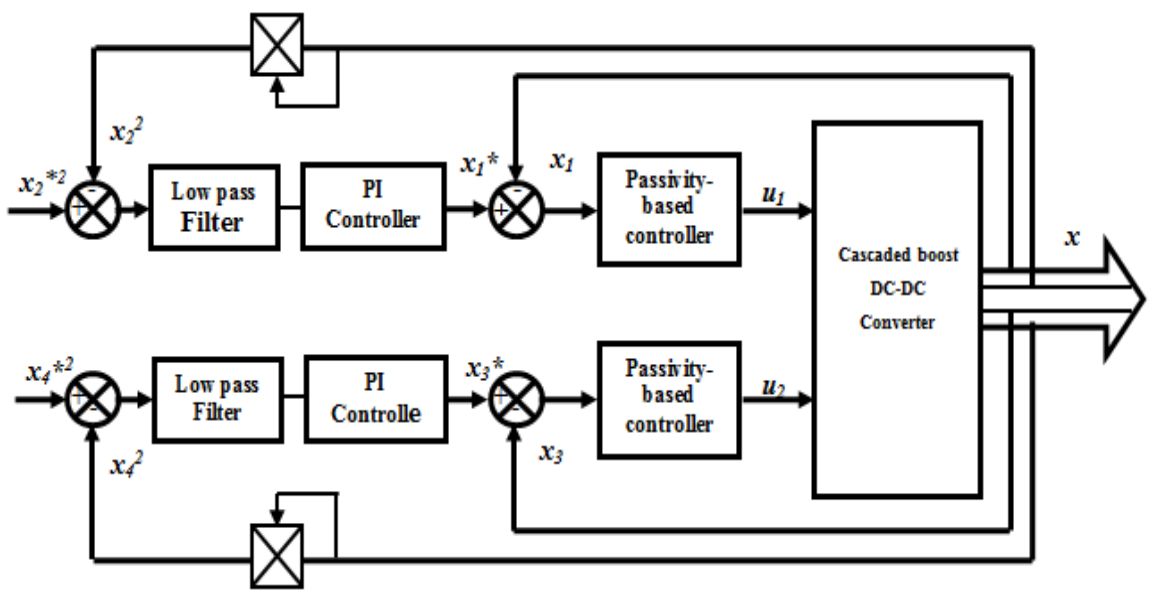

Figure 3. Controllers based structure 


\subsection{Inner loop}

Let $z=x-x^{*}$ denotes the tracking error matrix and consider the desired error dissipation matrix defined by:

$$
\mathcal{R}_{d}=\mathcal{R}+\mathcal{R}_{a}, \mathcal{R}_{a}=\operatorname{diag}\left(r_{a 1}, r_{a 2}, r_{a 3}, r_{a 4}\right)
$$

Where $\mathcal{R}_{a}$ denotes the injected damping and $r_{a 1}, r_{a 2}, r_{a 3}$ and $r_{a 4}$ are positive constants.

Performing a damping injection ensures the desired asymptotic behavior of the output error dynamics.

Using the Equations (3) and (5) and replacing $x$ by $\left(z+x^{*}\right)$ the error dynamics with desired damping become:

$$
\mathcal{D} \dot{z}+\mathfrak{I} z+\mathcal{R}_{d} z=\mathcal{E}-\left(\mathcal{D} \dot{x}^{*}+\mathfrak{I} x^{*}+\mathcal{R} x^{*}-\mathcal{R}_{a} z\right)
$$

The control laws will be define by the following expression.

$$
\mathcal{E}-\left(\mathcal{D} \dot{x}^{*}+\mathfrak{I} x^{*}+\mathcal{R} x^{*}-\mathcal{R}_{a} z\right)=0
$$

In this case the error dynamics is defined by:

$$
\mathcal{D} \dot{z}+\mathfrak{\Im} z+\mathcal{R}_{d} z=0
$$

We define the total energy as a Lyapunov function for Equation (8) as follows

$$
H=\frac{1}{2} z^{T} \mathcal{D} z
$$

To get a stabilizing control laws, the time-derivative $\dot{H}$ must be a negative definite function of $\mathrm{z}$. Then $\dot{H}$ is chosen as:

$$
\dot{H}=-z^{T} \mathcal{R}_{d} Z<0 \quad \text { for } z \neq 0
$$

Consider the expression (7)

$$
\mathcal{E}=\mathcal{D} \dot{x}^{*}+\mathfrak{I} x^{*}+\mathcal{R} x^{*}-\mathcal{R}_{a} z
$$

which corresponds to the following scalar differential equations :

$$
\left\{\begin{array}{c}
L_{1} \dot{x}_{1}^{*}+\left(1-u_{1}\right) x_{2}^{*}+r_{1} x_{1}^{*}-r_{a 1} z_{1}=V_{F C} \\
L_{2} \dot{x}_{3}^{*}-x_{2}^{*}+\left(1-u_{2}\right) x_{4}^{*}+r_{2} x_{3}^{*}-r_{a 3} z_{3}=0
\end{array}\right.
$$

Then, the control laws to satisfy a stabilization are defined by:

$$
\left\{\begin{array}{l}
u_{1}=1+\frac{1}{x_{2}^{*}}\left(L_{1} \dot{x}_{1}^{*}+r_{1} x_{1}^{*}-r_{a 1} z_{1}-V_{F C}\right) \\
u_{2}=1+\frac{1}{x_{4}^{*}}\left(L_{2} \dot{x}_{3}^{*}+r_{2} x_{3}^{*}-r_{a 3} z_{3}-x_{2}^{*}\right)
\end{array}\right.
$$

\subsection{Voltage outer loop control}

The aim is to design tuning laws for the $x_{1}{ }^{*}$ and $x_{3}{ }^{*}$.

We consider: $y_{2}=x_{2}^{2}$ and $y_{4}=x_{4}^{2}$

Using the Equation (2) we can establish the following relations

$$
\dot{y}_{2}=\frac{2 E}{C_{1}} x_{1}^{*}+\frac{2 z_{1} k_{1}}{C_{1}} x_{1}^{*}-\frac{L_{1}}{C_{1}} \frac{d}{d t}\left(x_{1}^{* 2}\right)-\frac{2 z_{1}}{C_{1}} \dot{x}_{1}^{*}+F(x, t) \text { and } \dot{y}_{4}=\frac{2}{C_{2}}\left[\begin{array}{c}
\left(k_{3} z_{3}+x_{2}-L_{2} \dot{x}_{3}^{*}\right)\left(\frac{z_{3}}{L_{2}}+x_{3}^{*}\right) \\
-\frac{2}{R} y_{4}
\end{array}\right]
$$

We must use a low pass filter for the first derivative $\dot{x}_{1}^{*}$ (respectively $\dot{x}_{3}^{*}$ ) of the reference $x_{1}^{*}$ (respectively $x_{3}^{*}$ ) exists, we obtain finally: 


$$
x_{1}^{*}=\frac{b}{s+b}\left(k_{p 2} Z_{2}+k_{i 2} Z_{22}\right) \quad \text { and } \quad x_{3}^{*}=\frac{b^{\prime}}{s+b^{\prime}}\left(k_{p 4} Z_{4}+k_{i 4} Z_{44}\right)
$$

with:

$$
\begin{aligned}
& F(x, t)=\frac{1}{C_{1}}\left(-2 \sqrt{y_{2}} x_{3}^{*}+\frac{2 k_{1}}{L_{1}} z_{1}^{2}+\frac{2 E}{L_{1}} z_{1}-\frac{2 z_{3}}{L_{2}} \sqrt{y_{2}}\right) \\
& \left\{\begin{array} { l } 
{ z _ { 2 } = y _ { 2 } ^ { * } - y _ { 2 } } \\
{ z _ { 2 2 } = \int z _ { 2 } d t }
\end{array} \text { and } \left\{\begin{array}{l}
z_{4}=y_{4}^{*}-y_{4} \\
z_{44}=\int z_{4} d t
\end{array}\right.\right.
\end{aligned}
$$

\section{RESULTS AND ANALYSIS}

In this section, the performances of the controller will be illustrated by simulations in the Matlab/Simulink environment. The controlled DC/DC converter has the following characteristics: $r_{a 1}=r_{a 2}=40 \Omega ; b=b^{\prime}=3 ; k_{p 2}=k_{p 4}=2 ; k_{i 2}=k_{i 4}=4$.

The converter has been simulated to check the previous stability conditions. The Figure 4 shows the fuel cell voltage. The output voltage of converter and his reference that having two values: $70 \mathrm{~V}$ and $140 \mathrm{~V}$ are shown in Figure 5. We observe that the tracking is satisfied and the stability is guaranteed.

To analyze the robustness capability of the proposed controller, a new experiment will be performed. It consists in changing the fuel cell voltage according to Figure 6. Except for this change, the rest of the converter characteristics are the same as previously. The Figure 7 shows that the effect of fuel cell voltage change is well compensated by the controller.

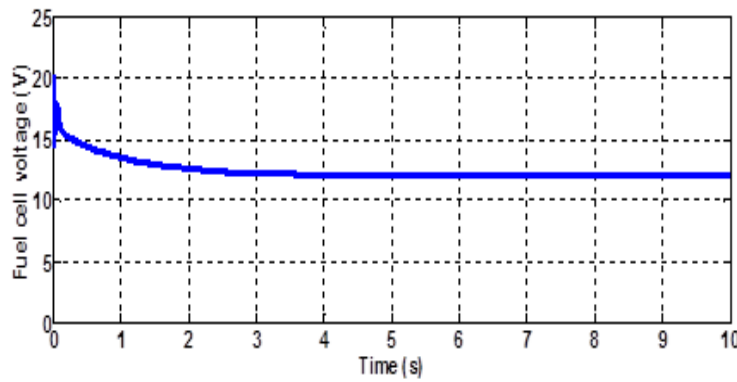

Figure 4. Fuel cell voltage versus time

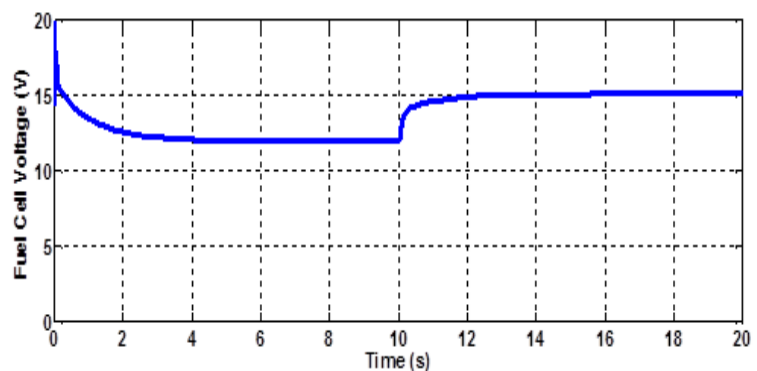

Figure 6. Fuel cell voltage versus time

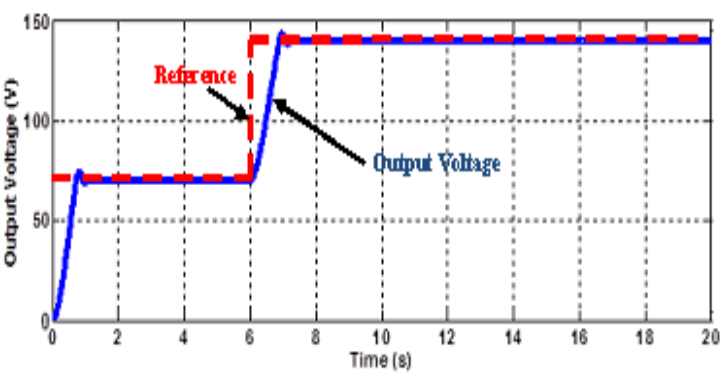

Figure 5. Output voltage with traking

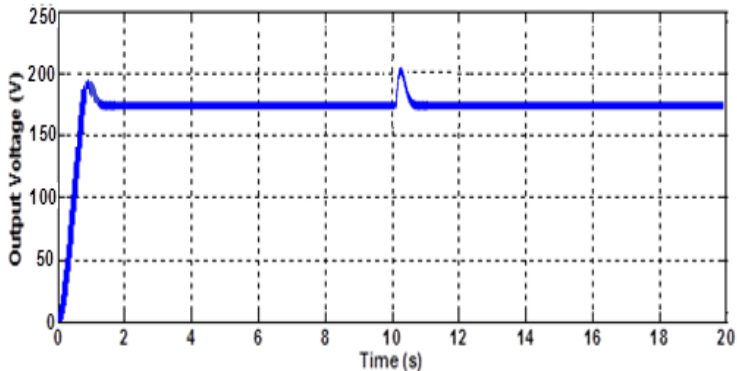

Figure 7. Output voltage with disturbance

\section{CONCLUSION}

The analysis and study of the insertion of fuel cell in power system is important in order to increase the competitiveness of this source.

A nonlinear controller is proposed for DC/DC cascaded boost converter to achieve voltage output regulation. It is developed in two steps. First, an inner-loop is designed, based on the passivity technique. The inner-loop regulator generates the duties cycle $\mu_{1}$ and $\mu_{2}$. The second step consists in developing an outerloop that generates the reference currents so that the squared output voltages $V_{C 1}\left(x_{2}\right)$ and $V_{O}\left(x_{4}\right)$ follows a given reference signals $x_{2}^{*}$ and $x_{4}^{*}$. The synthesis of this loop involves a linearizing variable change, a signal filtering to cope with model time-varying and controllability issues and a loop mode separation. 
A formal analysis and a simulation study prove that the proposed controllers actually meet its objectives: tracking, stability and robustness guarantied. The results obtained are similar to those of the sliding mode controller [12]-[14].

\section{REFERENCES}

[1] F. Outferdine, et al., "Feasibility of Substitution of the Conventional Street Lighting Installation by the Photovoltaic Case Study on a Municipality in Agadir in Morocco", IJECE, vol. 7, no. 5, pp. 2287-2299, October 2017.

[2] A. Ezzaidi, et al., "Evaluation of the Energy Performance of the Amougdoul Wind Farm, Morocco", IJECE, vol. 7, no. 2, pp. 692-705, April 2017.

[3] J.M.Correa, et al., "An Electrochemical Based Fuel Cell Model Suitable for Electrical Engineering Automation Approach”, IEEE Transactions on Industrial Electronics, vol. 51, pp. 1103-1112, Oct 2011.

[4] D.Fimoffen and M.Basualdo, "Advanced Control for Fuel Cells Connected to a DC-DC Converter and an Electric Motor", Computers and Chemical Engineering, 2010.

[5] Sira-Ramirez H., et al., "Passivity-based Controllers for the Stabilization of DC to DC Power Converters", Automatica, vol. 33, no. 4, pp. 499-513, 1997.

[6] Wu Lei-tao, et al., "Investigation of Passivity-based Control of DC/DC Converter", Transactions of China Electrotechnical Society, vol. 19, no. 4, pp. 66-69, 2004 (in Chinese).

[7] Xue Hua and Jiang Jian-guo, "Study on Adaptive Passivity-based Control Strategies of Shunt Active Filters". Proceedings of the CSEE 27(25), pp. 114-118, 2007 (in Chinese).

[8] Tzann-Shin Lee, "Lagrangian Modeling and Passivity-based Control of three-phase AC/DC Voltagesource Converters", Industrial Electronics, vol. 51, no. 4, pp. 892-902, 2004.

[9] Wang Jiu-he, "Passivity-based Control Theory and its Application", Beijing: Publishing House of Electronics Industry, 2010 (in Chinese).

[10] Qiao Shu-tong, et al., "Application of Passivity-based Sliding Mode Control in DC/ DC Converters", Transactions of China Electro-technical Society, vol. 18, no. 4, pp. 41-45, 2003)

[11] Li Hua-Wu and al, "An EL Model Based Passivity Control of four phase interleaved PFC", Archives of Electrical Engineering, vol. 62, pp. 613-628, 2013.

[12] Bin Huang, "Convertisseurs Continu - Continu à Rapport de Transformation Elevé pour Applications PAC", Thèse soutenue le 14 mai 2009.156 pages.

[13] A.M.Shahin, "Contribution à l'Optimisation des Structures de Conversion DC-DC Non Isolés", Thèse soutenue le 08 juillet 2011.162 pages.

[14] R. Saidi, "Convertisseur Basse Tension (42V,540V) Application Source Hybride Utilisant une PAC", Thèse soutenue le 11 mars 2015.147 pages.

[15] M. Hinaje, et al., "Modeling of the Proton Exchange Membrane Fuel Cell in Steady State", Power Electronics Specialists Conference, PESC 2008.

[16] H. Sira-Ramirez and R. Silva-Ortigoza, Control Design Techniques in Power Electronics Devices, 2006, XVIII, 424p, Hardcover, Springer. ISBN: 978-1-84628-458-8

\section{BIOGRAPHIES OF AUTHORS}

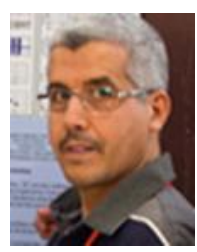

Moutabir Ahmed was born in 1965 in Casablanca, Morocco. He received the Engineer degree in electrical Engineering from High Institute of Technical Education (ENSET) of Mohammedia in 1989. In 1996, he successfully passed the external aggregation contest. He obtained his Master in Automatic, Signal Processing and Industrial Computing from Faculty of Sciences and Technics, University Hassan First, Settat, Morocco. Since 1995, he joined the technical school Alkhaouarimy of Casablanca where he teaches in classes BTS "Technician Certificate Superiors" in Casablanca, Morocco and pursues his doctoral studies at the University Hassan first Settat. His main research interests and experience include analysis, design, and control of power converters and renewable energy applications.

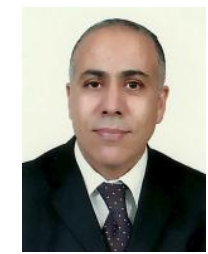

Elhassane Abdelmounim received his $\mathrm{PhD}$ in applied Spectral analysis from Limoges University at science and technical Faculty, France in 1994.

in 1996, he joined, as Professor, applied physics department of science and technical faculty, Hassan $1^{\text {st }}$ University, Settat, Morocco His current research interests include digital signal processing and machine learning. He is currently coordinator of a Bachelor of Science in electrical engineering and researcher in "ASTI" System Analysis and Information Technology Laboratory at science and technical faculty, Hassan $1^{\text {st }}$ University, Settat, Morocco. 


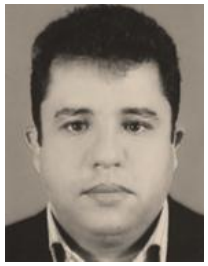

Mohamed aboulfatah was born in Casablanca Morocco in 1967, he received his $\mathrm{PhD}$ in Measures and Instrumentation from Bordeaux University, France in 1994. From 1993 to 1995 he was associated professor at the Technological Institute of Bordeaux University. in 1996, he joined, as permanent Professor, applied physics department of science and technical faculty, Hassan $1^{\text {st }}$ University, Settat, Morocco. He is currently head of Applied Physics department and coordinator of "Automatic, Signal Processing and Industrial Computing" Master. His main research interests and experience include Instrumentation, Signal Processing. as a researcher member of ASTI Laboratory in Hassan 1st University. 